\title{
Lung delivery of salbutamol by dry powder inhaler (Turbuhaler®) and small volume antistatic metal spacer (Airomir® CFC-free MDI plus NebuChamber®)
}

\author{
B.J. Lipworth, D.J. Clark
}

Lung delivery of salbutamol by dry powder inhaler (Turbuhaler $\left.{ }^{\circledR}\right)$ and small volume antistatic metal spacer (Airomir ${ }^{\circledR}$ CFC-free MDI plus NebuChamber ${ }^{\circledR}$ ). B.J. Lipworth, D.J. Clark.

ABSTRACT: As a worldwide ban on the use of chlorofluorocarbons (CFCs) in inhaler devices approaches, considerable attention has been focused on the production of CFC-free delivery devices. The aim of our study was to compare the delivery of salbutamol by dry powder inhaler (DPI), Turbuhaler ${ }^{\circledR}$ and a CFC-free metered-dose inhaler (MDI), Airomir ${ }^{\circledR}$, used with a novel small volume metal spacer (NebuChamber $\left.{ }^{\circledR}\right)$.

Ten healthy volunteers, mean (SEM) age $21(0.7)$ yrs were studied in a randomized, single (investigator)-blind cross-over design. Single doses of 1,200 $\mu \mathrm{g}$ salbutamol, from Turbuhaler ${ }^{\circledR}$ DPI and Airomir ${ }^{\circledR}$ CFC-free MDI via a NebuChamber ${ }^{\circledR}$, were given as 12 sequential $100 \mu \mathrm{g}$ inhalations over $6 \mathrm{~min}$. The lung delivery of salbutamol was assessed by measuring the plasma salbutamol profile over the first 20 min after inhalation. Plasma salbutamol concentration was expressed as maximal $(\mathrm{C} \max )$ and average $(\mathrm{Cav})$ value.

Significant differences $(\mathrm{p}<0.001)$ were found between the NebuChamber ${ }^{\circledR}(\mathrm{N})$ and the Turbuhaler ${ }^{\circledR}(\mathrm{T})$ for salbutamol $\mathrm{Cmax}$ and $\mathrm{Cav}$. This amounted to a 1.89 fold difference (95\% CI 1.56-2.22) between these devices for Cmax, and a 1.78 fold difference (95\% CI 1.42-2.15) for Cav.

We have demonstrated that, in vivo, salbutamol from a chlorofluorocarbon-free metered-dose inhaler given via a small volume metal spacer (NebuChamber ${ }^{\circledR}$ ) produces significantly greater delivery than from an efficient dry powder inhaler (Turbuhaler®).

Eur Respir J 1997; 10: 1820-1823.

Dept of Clinical Pharmacology, Ninewells Hospital \& Medical School, University of Dundee, Dundee, UK.

\section{Correspondence: B.J. Lipworth} Dept of Clinical Pharmacology Ninewells Hospital and Medical School University of Dundee

Dundee DD1 9SY

UK

Keywords: Antistatic metal spacer bioavailability chlorofluorocarbon deposition dry powder inhaler salbutamol

Received: November 41996 Accepted after revision April 121997

This study was not sponsored by the pharmaceutical industry.
As a worldwide ban on the use of chlorofluorocarbons (CFCs) in inhaler devices approaches [1], the pharmaceutical industry has been involved with the production of CFC-free delivery devices. These include both dry powder inhalers (DPIs) and metered-dose inhalers (MDIs) using non-CFC propellants. The aim of the present study was to compare the delivery of salbutamol from the Turbuhaler® DPI, shown to be one of the most efficient DPIs available [2-5], and a CFC-free MDI used with a novel small volume metal spacer (NebuChamber $\left.{ }^{\circledR}\right)$. The NebuChamber® is a $250 \mathrm{~mL}$ antistatic spacer device, which has been demonstrated to reduce the problem of static charge, which can affect large volume plastic spacers $[6,7]$. Static charge has been demonstrated to be a problem, in that it can affect the drug delivery both of corticosteroids and salbutamol inhaled via small and large volume plastic spacers [7-10].

We have previously demonstrated that the pharmokinetic profile of salbutamol in the first $20 \mathrm{~min}$ after inhalation represents the bioavailability from the lung but not the gastro-intestinal tract, with the latter moiety contributing $0.3 \%$ to the overall systemic bioavailability from an inhaled dose $[11,12]$. This method of measuring lung bioavailability of salbutamol can, therefore, be applied to compare the lung deposition from different inhaler devices [13-15].
It is also worth noting that both of these inhaler devices overcome the problem of poor inhaler technique, which is recognized as a common problem with asthmatics, particularly when using standard MDIs. We were, therefore, interested in establishing whether significant differences exist in vivo in terms of lung delivery of salbutamol given by DPI (Turbuhaler@) and by a small volume antistatic metal spacer (NebuChamber®).

\section{Materials and methods}

Ten healthy volunteers, mean (SEM) age 21 (0.7) yrs, forced expiratory volume in one second (FEV1) 105 (3)\% of predicted, were studied in a randomized, single (investigator)-blind, cross-over design. Single doses of 1,200 $\mu \mathrm{g}$ salbutamol from Inspiryl Turbuhaler ${ }^{\circledR}$ (Astra Draco, Lund, Sweden) and Airomir® MDI (3M Healthcare Ltd, Loughborough, UK) via a NebuChamber® without mask (Astra Draco, Lund, Sweden) were given as 12 sequential $100 \mu \mathrm{g}$ inhalations over $6 \mathrm{~min}$. Mouth rinsing was performed after every inhalation to further obviate the possibility of a small amount of gastro-intestinal absorption.

The subjects were studied on 2 days separated by 1 week. They were carefully instructed in inhalation technique, as described by the manufacturers' literature. A 
Turbuhaler® training device (Astra Draco, Sweden) was used to ensure an optimal peak inspiratory flow rate of at least $60 \mathrm{~L} \cdot \mathrm{min}^{-1}$. The NebuChamber ${ }^{\circledR}$ was used for breathing from residual volume (RV) to total lung capacity (TLC), using single puffs with immediate inhalation from the spacer. Plasma salbutamol was measured at 5, 10,15 and $20 \mathrm{~min}$. Systemic $\beta_{2}$-responses were measured as plasma potassium, tremor and cardiac frequency $(f \mathrm{C})$ taken at baseline, 5, 10, 15 and 20 min (all measurements made with the subject supine).

\section{Measurements}

Finger tremor was measured using a previously validated method employing an accelerometer transducer (Entran, Ealing, UK) [16]. Cardiac frequency was measured from standard lead II of an electrocardiogram (ECG) monitor. Plasma potassium was assayed by flame photometry using an IL943 analyser (Instrumentation Laboratory Ltd, Warrington, UK). The intra-assay and interassay values for analytical imprecision were 0.41 and $1.04 \%$, respectively.

Plasma salbutamol was assayed by high-performance liquid chromatography (HPLC), the extraction process using silica adsorption with chromatography followed by reverse phase ion pair HPLC and electrochemical detection. The analytical imprecision for plasma salbutamol was $7.8 \%$ (intra-assay) and $6.7 \%$ (interassay). The HPLC detection limit for salbutamol was $0.02 \mathrm{ng} \cdot \mathrm{mL}^{-1}$.
Plasma concentrations were expressed as maximal (Cmax) and average (Cav) values over the 5, 10, 15 and 20 min time-points.

\section{Statistical analysis}

The results were analysed using the "statgraphics" statistical software package (STSC Software Publishing Group, Rockville, USA). For all parameters, comparisons were made by multifactorial analysis of variance (MANOVA). A p-value of less than 0.05 (two-tailed) was considered significant.

\section{Results}

Significant differences were found between the NebuChamber ${ }^{\circledR}$ and the Turbuhaler ${ }^{\circledR}$ for salbutamol $\mathrm{Cmax}$ and Cav as shown in figure 1 and table 1 . The NebuChamber® produced significantly $(\mathrm{p}<0.001)$ higher salbutamol levels: Cmax N 6.80 vs T $3.76 \mathrm{ng} \cdot \mathrm{mL}^{-1}$ (95\% CI for difference $\left.2.41-3.66 \mathrm{ng} \cdot \mathrm{mL}^{-1}\right)$; Cav N 5.82 vs T $3.44 \mathrm{ng} \cdot \mathrm{mL}^{-1}$ (95\% CI for difference $1.50-3.26 \mathrm{ng} \cdot \mathrm{mL}^{-1}$ ). There was a 1.89 fold difference (95\% CI 1.56-2.22) between these devices for $\mathrm{C}_{\max }$, and a 1.78 fold difference $(95 \%$ CI 1.42-2.15) for Cav. Individual data for Cmax are presented in figure 2 , and show only one overlapping value between the two devices. There were no significant differences between the devices in terms of time to maximal concentration $(T \max )$ for salbutamol.
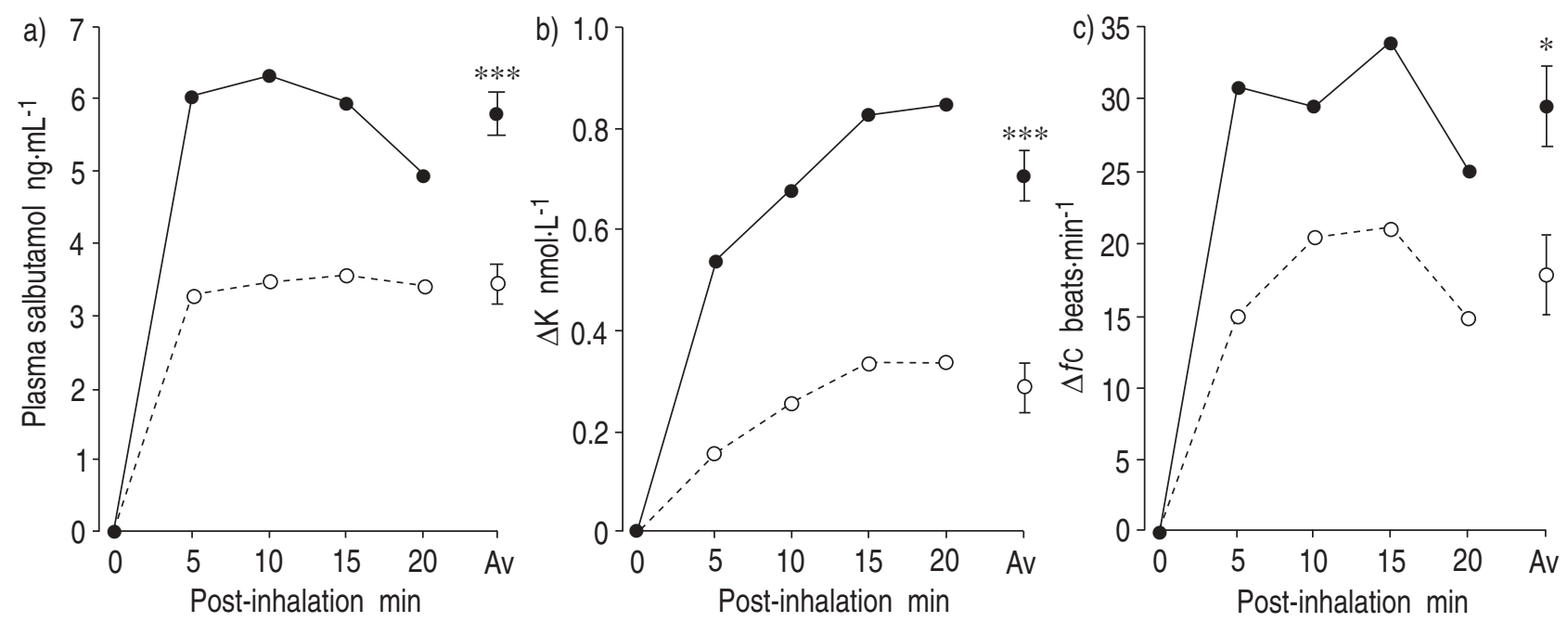

Fig. 1. - a) The mean plasma salbutamol concentration; b) the decrease in plasma potassium $(\Delta \mathrm{K})$; and $\mathrm{c})$ the increase in cardiac frequency $(\Delta f \mathrm{C})$, at 5,10,15 and $20 \mathrm{~min}$ after inhalation of salbutamol. The average (Av) for all time-points is also shown with sEM. *: $\mathrm{p}<0.05$; $* * *: \mathrm{p}<0.001$,

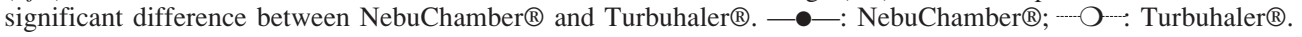

Table 1. - Average and maximal values for plasma salbutamol level, fall in plasma potassium $(\Delta \mathrm{K})$ level, increase in cardiac frequency $(f c)$, and Tmax values for each parameter

\begin{tabular}{|c|c|c|c|c|}
\hline & & Salbutamol & $\Delta \mathrm{K}$ & $\Delta f \mathrm{C}$ \\
\hline \multirow[t]{2}{*}{ Average } & NebuChamber® ${ }^{\circledR}$ & $5.82(1.50-3.26)^{*}$ & $0.71(0.25-0.60)^{*}$ & $29.6(2.8-20.5)^{*}$ \\
\hline & Turbuhaler® & 3.44 & 0.29 & 17.9 \\
\hline \multirow[t]{2}{*}{ Maximum $*$} & NebuChamber® ${ }^{\circledR}$ & $6.80(2.41-3.66)^{*}$ & $0.86(0.32-0.67)^{*}$ & $40.5(1.7-27.3)^{*}$ \\
\hline & Turbuhaler® & 3.76 & 0.37 & 26.0 \\
\hline \multirow[t]{2}{*}{$\mathrm{Tmax}^{\#}$} & NebuChamber® & $10(5-15)$ & $20(10-20)$ & $10(5-20)$ \\
\hline & Turbuhaler® & $10(5-20)$ & $20(10-20)$ & $10(5-15)$ \\
\hline
\end{tabular}

$\$$ : mean value, and $95 \%$ confidence interval for the difference between treatments in parenthesis; \#: median, and range in parenthesis. *: $\mathrm{p}<0.05$, significant difference between treatments. Tmax: time to maximal concentration/response. 


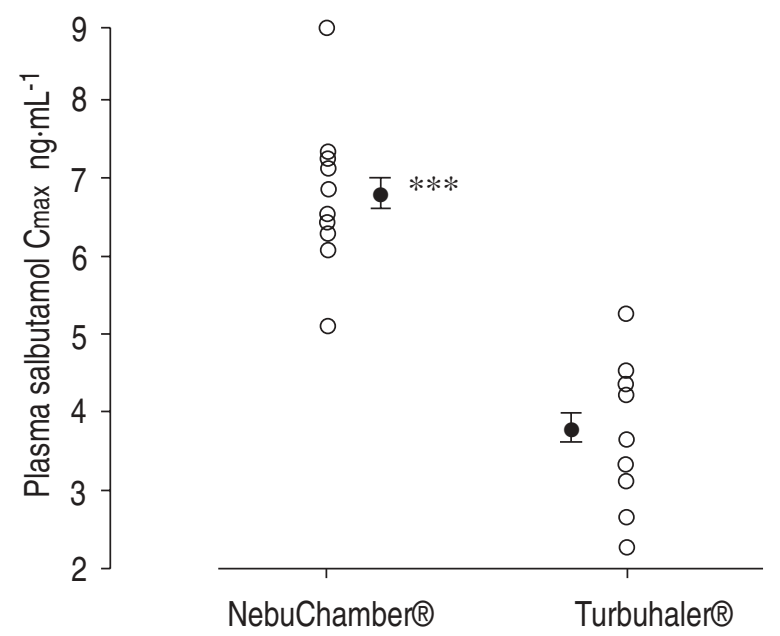

Fig. 2. - Individual values for maximal plasma salbutamol concentration $(\mathrm{C} \max )$, comparing the NebuChamber® and Turbuhaler®. Mean values $(\bullet)$ and SEM are also presented. ***: $\mathrm{p}<0.001$, for comparison between the devices.

Differences were also found with systemic $\beta_{2}$-responses, in keeping with the pharmacokinetic data (table 1). These differences were highly significant both for cardiac frequency and plasma potassium, as shown in figure 1. For tremor the same trend was seen; however, the differences were not significant (log units for average), NebuChamber® (0.68), Turbuhaler® (0.49).

\section{Discussion}

We found that, in vivo, delivery of non-CFC salbutamol aerosol via a small volume metal spacer (NebuChamber $\left.{ }^{\circledR}\right)$ was significantly greater than salbutamol via an efficient DPI (Turbuhaler@). This amounted to almost a twofold difference in salbutamol bioavailability between these devices, which was also mirrored by dynamic responses. The use of the $20 \mathrm{~min}$ plasma salbutamol profile reflects absorption from the lung but not from the gastro-intestinal tract, with the latter contributing only $0.3 \%$ to the overall bioavailability when given by the inhaled route. However, it is unclear what proportion of this absorption originates from alveolar or bronchial sites.

It is important to determine whether differences in lung deposition of salbutamol are likely to result in commensurate improvements in bronchodilator response. For most patients with stable asthma, $200 \mu \mathrm{g}$ of salbutamol will result in a bronchodilator response approaching the top of the dose-response curve. However, in more severely affected patients or during an acute attack, much higher doses are required to optimize the bronchodilator response on the steep part of the curve [17]. In a study of patients with moderately severe asthma comparing two nebulizers with different respirable dose outputs, it was shown that an increase in lung bioavailability of salbutamol was associated with an improved bronchodilator response [18]. In the setting of acute severe asthma, it is, therefore, possible that an improved bronchodilator response may be achieved with better lung deposition, although this factor can be obviated simply by administering a greater number of puffs to achieve the same response.
An important point to make regarding the present results is that they relate only to salbutamol in these specific inhaler devices. The Turbuhaler ${ }^{\circledR}$ is accepted as an efficient inhaler device, with similar figures for radiolabelled deposition both for the corticosteroid, budesonide, and the $\beta_{2}$-agonist, terbutaline [3]. However, it may be the case that salbutamol lung deposition from the Turbuhaler ${ }^{\circledR}$ is not as great as for terbutaline or budesonide, although we are not aware of any such comparative data.

It is also possible that the results seen with the NebuChamber® may reflect the use of a non-CFC salbutamol MDI formulation, and that comparable deposition would not be achieved with a CFC formulation. It is also worth pointing out that in everyday clinical practice, effects of static charge will have minimal impact with the metal NebuChamber ${ }^{\circledR}$, in terms of obviating effects of multiple puffs or inhalation delay [7]. Hence, it is likely that the results of our study using single puffs without delay will be equally applicable to what happens in real life.

In conclusion, plasma salbutamol pharmacokinetic measurement for determining lung bioavailability provides a sensitive method for comparing deposition of inhaler devices in vivo. In this study, salbutamol from a chlorofluorocarbon-free salbutamol metered-dose inhaler via the NebuChamber ${ }^{\circledR}$ produced significantly greater lung bioavailability than salbutamol from a dry powder inhaler, Turbuhaler®.

\section{References}

1. Partridge MR. Metered-dose inhalers and CFCs: what respiratory physicians need to know. Respir Med 1994; 88: 645-647.

2. Olsson B. Aerosol particle generation from dry powder inhalers: Can they equal pressurised metered-dose inhalers? J Aerosol Med 1995; 8 (Suppl. 3): S13-S18.

3. Borgstrom L, Bondesson E, Moren F, Trofast E, Newman SP. Lung deposition of budesonide inhaled via Turbuhaler ${ }^{\circledR}$ : a comparison with terbutaline sulphate in normal volunteers. Eur Respir J 1994; 7: 68-73.

4. Ekstrom T, Andersson A, Skedinger M, Lindbladh C, Stahl E. Dose potency relationship of terbutaline inhaled via Turbuhaler or via a pressurised metered-dose inhaler. Ann Allergy Asthma Immunol 1995; 74: 328-332.

5. Borgstrom L, Derom E, Stahl E, Wahlin-Boll E, Pauwels $\mathrm{R}$. The inhalation device influences lung deposition and bronchodilating effect of terbutaline. Am J Respir Crit Care Med 1996; 153: 1636-1640.

6. Bisgaard H, Anhoj J, Klug B, Berg E. A nonelectrostatic spacer for aerosol delivery. Arch Dis Child 1995; 73: 226-230.

7. Wildhaber JH, Devadason SG, Eber E, et al. Effect of electrostatic charge, flow, delay and multiple actuations on the in vitro delivery of salbutamol from different small volume spacers for infants. Thorax 1996; 51: 985-988.

8. Barry PW, O'Callaghan C. The effect of delay, multiple actuations and spacer static charge on the in vitro delivery of budesonide from the Nebuhaler. $\mathrm{Br} J$ Clin Pharmacol 1995; 40: 76-78.

9. Barry PW, O'Callaghan C. Multiple actuations of salbutamol MDI into a spacer device reduce the amount of drug recovered in the respirable range. Eur Respir $J$ 1994; 7: 1707-1709. 
10. Clark DJ, Lipworth BJ. Effect of multiple actuations, delayed inhalation and antistatic treatment on the lung bioavailability of salbutamol via a spacer device. Thorax 1996; 51: 981-984.

11. Lipworth BJ. Pharmacokinetics of inhaled drugs. $\mathrm{Br} J$ Clin Pharmacol 1996; 42: 697-705.

12. Chrystyn H, Corlett SA, Silkstone V. Lung bioavailability of generic and innovator salbutamol MDIs. Thorax 1996; 51: 658.

13. Newnham DM, McDevitt DG, Lipworth BJ. Comparison of the extrapulmonary $\beta_{2}$-adrenoceptor responses and pharmacokinetics of salbutamol given by standard metereddose inhaler and modified activator device. Br J Clin Pharmacol 1993; 36: 445-450.

14. Clark DJ, Lipworth BJ. Lung bioavailability of chlorofluorocarbon-free, dry powder and chlorofluorocarbon- containing formulations of salbutamol. Br J Clin Pharmacol 1996; 41: 247-249.

15. Clark DJ, Gordon-Smith J, McPhate G, Clark G, Lipworth BJ. Lung bioavailability of generic and innovator salbutamol metered-dose inhalers. Thorax 1996; 51: 325326.

16. Lipworth BJ, McDevitt DG. Beta-adrenoceptor responses to inhaled salbutamol in normal subjects. Eur J Clin Pharmacol 1989; 36: 239-245.

17. Clark DJ, Lipworth BJ. Dose-response of inhaled drugs in asthma: an update. Clin Pharmacokinet 1997; 32: $58-74$

18. Newnham DM, Lipworth BJ. Nebuliser performance: pharmacokinetics and systemic effects of salbutamol given via a novel nebuliser delivery system (Ventstream). Thorax 1994; 49: 762-770. 